Although I could write excellent essays, I could not talk on the phone, or tie my shoelaces. My difficulties were increasing with age, but I was unable to get any recognition of this, due to the fact that my academic ability was well above average in most subjects.

Reaching the age when my peers and I were entering the working world, I was still very under-prepared to function in this milieu. I managed to hold down jobs for a time, but found social relating, learning new tasks, multi-tasking, and making errors, very stressful. Eventually, I suffered a series of nervous breakdowns, three times ending up in a psychiatric hospital. The second stay was for eight months, and included issues of institutional abuse. My diagnoses included "schizophrenia", "borderline personality disorder", "manic depression", "anxiety disorder", and "the beginning stages of multiple personality disorder."

Far from being helped by these experiences, I continued to struggle on with anxiety, depression and confusion during my thirties. My inability to read facial expressions and body language, and whether people were joking or not, meant that I often made incorrect judgement calls. I told my Mum that I felt like "an alien from outer space." I drew some comfort from my passions of reading and poultry keeping. I knew that I was still good at studying, so in my late thirties, I decided to take a Bachelor of Arts paper at the University of Auckland. I became hooked, eventually enrolling for full-time study, supported by the adult student allowance. At the age of 39 I also met a man who was able to love me in spite of my oddities. We live far apart but still have our special long-distance friendship.

On campus, I attended every lecture in my own subjects (German, Comparative Literature, Linguistics, Anthropology, English), and any extra seminars I could fit in. Revelling in the intellectual stimulation, I soon discovered that I could attain high marks in coursework. My essays for German Literature and Comparative Literature always achieved an A or an A+. The magic ingredient, for me, was that coursework essays allowed me months in which to write them: I could think about the essay topic, research it, and write it over a long period, perfecting it as I went.

The exact opposite is the case for exam essays. One has, for example, two hours in which to write two separate essays, or three hours for three essays. This puts a completely different time-frame, and a lot of urgency, on to the task. As well as that was the considerable stress I experienced in finding the correct exam room at short notice (deliberately arranged to be short notice by the university, as an anticheating strategy). This often meant that I was already very anxious by the time I had found the room. Added to all of that was the difficulty of having to switch my brain, suddenly and completely, from writing essay number one to essay number two (and, sometimes, essay number three) - all within a short time-frame. In other words, I was not allowed to keep concentrating on the topic in hand, but, just when I was getting deeply into it, I would be forced to switch to a new topic - otherwise, of course, one would attempt only a proportion of the questions, and would fail the exam as a result.
The factors which are noteworthy in the exam context familiarisation with the environment beforehand, performance anxiety, difficulty with sudden new requirements, transition, and switching one's concentration to a new stimulus are amongst the factors which have been significant for me in all areas throughout my life, and still are.

This situation caused such a wide split in my coursework performance versus my exam performance that at least one teacher had difficulty understanding what was going on. This also caused me great frustration and anguish, when I had a coursework grade of A+ and was top of the class, only then to fall several grades in my final assessment, because of my inability to cope with the exam requirements. The same can be said for any environment, including the workplace, in which my work on a continuous project might well be excellent, but when I am quickly changed from one task to another in an atmosphere of urgency, I may not be able to function at all. I have tried to improve in this area, but I can still have considerable difficulties when such situations occur.

With one semester of my B.A. to go, I attended a seminar by Dr. Angela Arnold of the Department of Psychology, having no idea of what I was about to hear. Dr. Arnold described a particular developmental disorder which affects one in every 300 persons, world-wide, and listed its characteristics.

Shock waves hit me and I started shaking. Afterwards, I managed to detain Dr. Arnold before she left the room. We arranged a formal appointment and it became official: I have Asperger syndrome, (a condition on the higherfunctioning end of autism spectrum disorders: ASD), diagnosed at the age of 43. A lifetime burden of inadequacy, guilt, confusion and fear was lifted from me.

I graduated with my B.A. in 1999 and then began voluntary work for Autism New Zealand (Auckland Branch), which also caters for people with Asperger syndrome. Having Asperger suddenly became a plus, because my insider perspective meant that I could now give reassurance, advice and authentic knowledge to families who contacted Autism NZ

Finding out the reason why I had always had certain differences and difficulties felt like a blessing straight from heaven. When one grows up feeling increasingly different from other people - no matter how hard one tries to be "normal" - one can easily come to believe that one is inadequate in some way - that one must be "mad or bad." Once having reached that conclusion, a person can easily fall prey to anxiety, depression, and/or other mental illnesses. At the same time as this is going on, there is the interweaving of, and reinforcement by, frequent negative everyday events, such as disastrous social interactions inadvertently caused by the undiagnosed ASD traits - thus creating a real downward spiral from which there is no escape, without the proper explanation of what is happening and why. This happened not only to me, but, as I now know (due to having since met many other Asperger adults), this is a frequent outcome of late diagnosis. 
Children who are diagnosed with Asperger syndrome or autism, and who receive the appropriate support thereafter, should not then feel the need to blame themselves for their differences ... thus avoiding a huge amount of needless psychological suffering (not to mention inappropriate mental illness treatments).

Feeling passionately that the same scenario should not keep happening to others, I wrote my book Congratulations! It's Asperger syndrome.

The title was chosen to accentuate the positives, and celebrate the uniqueness, of individuals with Asperger and autism: vive la difference! 'Congratulations!' also conveys agreement with Dr. Tony Attwood, world expert on Asperger syndrome, who has been known to deliver the diagnosis with the words "Congratulations! Your child has Asperger syndrome!"

I wrote down all of the difficulties and "oddities" that I could remember, along with the reasons that I did things, and the outcomes that resulted, as I was trying to produce a "cause and effect" explanation. Some of my insights were new information to the autism world, hitherto unpublished. I was not to know, until my book was in the public arena, that many, many readers would respond with great enthusiasm to what I had described: parents and other family members said that my book helped them to understand their child with Asperger or autism. Many adults with Asperger themselves (including adults who would later follow up with their own official diagnosis) identified very strongly with my account.

As in my own case, the majority of adult Asperger individuals - as well as the parents of most individuals with Asperger of any age - welcome the diagnosis of Asperger syndrome, when this is the explanation which most obviously fits the case. This is because with the correct diagnosis comes understanding, and access to whatever resources are available for the condition. Parents, teachers, caregivers, and the affected persons themselves, can obtain helpful strategies which improve the life of the individual with Asperger or autism - once the correct diagnosis of ASD is supplied. Without the right explanation of why the person is different, he or she is likely to be labelled 'wilfully disobedient', 'lazy', 'not trying hard enough', and a host of other mis-explanations, along with a range of mis-treatments to fit the mis-explanations. Being treated unfairly and inappropriately is likely to distress the individual with ASD further, making further autistic behaviours more likely, followed by further mis-explanations and mis-treatments ... thus creating a negative cycle and unhappiness all round ... unless the correct explanation of the person's differences comes to light, enabling the correct interventions to be made.

Many families have found that as soon as they began interacting with their family member with ASD in a way that is appropriate for ASD, the family member began functioning better and the problems became fewer or easier to deal with. For example, the vast majority of individuals with ASD process information more effectively through the visual sense. Having established that the person in question is in this majority group, it is then better to communicate with the person as much as possible via the visual sense.
This can be done by using wall charts to show the day's routine and the week's routine; using picture checklists to show how tasks are done step by step; and using pen and paper (or email) for communication, or at least as a visual back-up for what was said in a verbal communication. The use of visual aids in ASD is now a recognised strategy, and interested persons can learn more about it via Autism $\mathrm{NZ}$ or other practitioners in the autism field.

A person with an undiagnosed ASD is probably not receiving the strategy of visual aids, or any other interventions which help persons on the spectrum. Improved quality of life is a prime reason why individuals with ASD should be identified as early as possible.

"Empowering" is a concept that I, as an adult of late diagnosis, use to describe what the explanation feels like. Instead of continuing to feel "mad or bad", I now know that I was merely born with slightly different brain wiring, and knowing what that entails, I can live my life far more effectively. With this relatively new information, I can now plan, organise and strategise to maximise my efficiency and to minimise failures. For instance, now that I know why I had big problems working in a café - due to the ASD deficit in multi-tasking ability - I have placed café work at the very bottom of my future careers list! Rather than continue to experience unnecessary failure, I now concentrate my efforts on the activities I can do, and the activities I have to do not the activities which cause me needless stress. Nowadays, I can often work my way around challenges, due to my new understanding of what I find easiest and what I find most difficult. Without the knowledge of why I sometimes need to do things differently from other people, I would still be "banging my head against a brick wall" trying to force myself to do it their way at all costs. I am now empowered to work smarter.

During the seven years since my diagnosis, I have given talks, training sessions and classes, including a Keynote Speech for Autism New Zealand's national conference in 2002, and have participated in several television documentaries on autism.

Whether they know it or not, people in all of the professions are working with individuals who have ASD. Autism NZ now estimates that one in every hundred persons is on the autism spectrum - so it is impossible to go through life without meeting some of us! Because many of these individuals are still undiagnosed and are therefore not receiving the appropriate support, it is essential for all professional people to become aware of the features of ASD. They can then assist by getting the individual referred for assessment, or at least by relating to the individual in the most helpful way.

Congratulations! It's Asperger syndrome, by Jen Birch, (Jessica Kingsley Publishers, London, 2003), 270 pages, is available world-wide, as well as available from myself, and is in many libraries. 


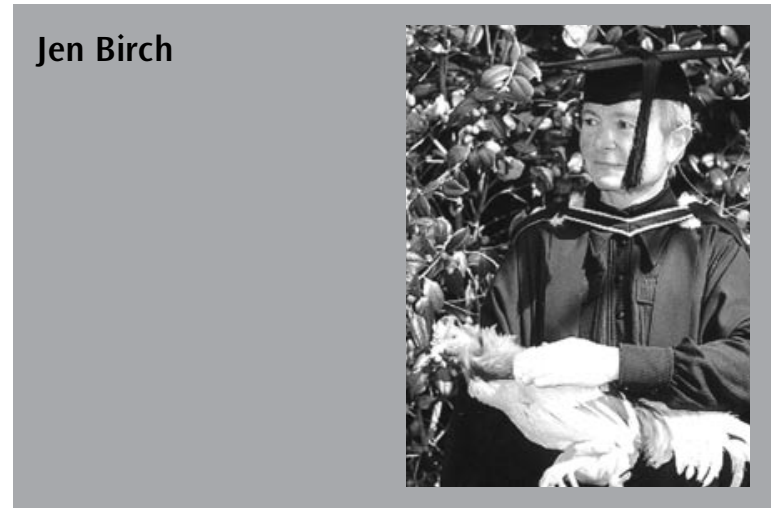

\section{AUTHOR PROFILE}

Jen Birch grew up in rural New Zealand knowing something was different about her. None of the professional services could help.

Jen began university study in her forties, one day attending a psychology lecture on Asperger syndrome. Recognising the traits, Jen arranged for an assessment, thus obtaining the diagnosis at 43 years of age.

Wishing to address the low awareness of ASD in New Zealand, Jen then wrote a book: Congratulations! It's Asperger syndrome (Jessica Kingsley Publishers, London, 2003). Jen also speaks at conferences and in the community on this subject.

\section{Author contact}

Please contact me if you would like me to speak to your organisation or group, or for any enquiries:

Jen Birch

P.O. Box $17-426$

Greenlane

Auckland

New Zealand

\section{Email}

jenbirch@actrix.gen.nz

\section{Website}

www.aspergers.co.nz 